Methods Document analysis and interviews were conducted to various duty of care bearers.

Results The high incidence in occupational accidents, injuries and diseases is a manifestation that the battle towards decent work and safe work environments in the Philippines has a long way to go. The discrepancy on the law versus practice of OSH Standards in the Philippines is evident. The number of establishments, the archipelagic nature of the country's geography, the low awareness on $\mathrm{OSH}$, and the lack of manpower from government agencies are just some major reasons why managing OSH in the Philippines is a very daunting task. Conclusions The nature of prevention measures on $\mathrm{OSH}$ in the Philippines can be described as a combination of both reactive and proactive policies. Considering the complexity of the challenges, issues and concerns involved, a holistic, integrated approach is therefore needed to upgrade the OSH situation in the Philippines.

\section{THE IMPACT OF SUSTAINED HOT WEATHER ON RISK OF ACUTE WORK-RELATED INJURY IN MELBOURNE, AUSTRALIA}

${ }^{1} \mathrm{JA}$ Mclnnes, ${ }^{1} \mathrm{EM}$ MacFarlane, ${ }^{1} \mathrm{MR}$ Sim* ${ }^{*}{ }^{1,2} \mathrm{P}$ Smith. ${ }^{1}$ Monash University Centre for Occupational and Environmental Health, Melbourne, Australia; ${ }^{2}$ Institute for Work and Health, Toronto, Canada

\subsection{6/oemed-2018-ICOHabstracts.73}

Introduction Increasing global temperatures will expose workers to hot days more often. The aim of this study was to quantify the impact of exposure to consecutive days of hot weather on the risk of work-related injury in Melbourne, Australia.

Methods A time-stratified case crossover study design was utilised to examine the association between 2 and 3 consecutive days and 2 and 3 consecutive nights of hot weather and risk of work-related injury, using definitions of hot weather ranging from the 60th to the 95th percentile of daily temperatures for the Melbourne metropolitan area, 2002-2012. Workers' compensation claim data were used to identify cases of workrelated injury.

Results Overall, 2 and 3 consecutive days of hot weather was associated with an increased risk of injury for workers. This effect became apparent at $27.6^{\circ} \mathrm{C}$, equivalent to the 70 th percentile of maximum temperature distributions during the study period. Exposure to three days of hot weather and the highest temperatures was associated with the strongest effect, with a $15 \%$ increased risk of injury (OR: $1.15,95 \% \mathrm{CI}: 1.01$ to 1.30) for workers exposed to temperatures $\geq 33.3^{\circ} \mathrm{C}$ (90th percentile) for 3 consecutive days, compared to those who were not. At a threshold of $35.5^{\circ} \mathrm{C}$ (95th percentile) there was no significant association between temperature and injury for either 2 or 3 consecutive days of heat. No consistent pattern was observed for hot nights, either with increasing levels of the temperature threshold or between two and three hot nights of exposure.

Conclusions Significant associations between consecutive days of hot weather and risk of work-related injury were apparent at relatively mild temperatures. These findings suggest warnings to minimise injury risk to workers from hot weather should be given and prevention protocols initiated when consecutive days of temperatures lower than extreme temperatures are forecast and before extreme temperatures are reached.
153 ORGANISATIONAL SOCIAL CAPITAL: THE MISSING LINK BETWEEN ORGANISATIONAL CULTURE AND SAFETY AWARENESS

${ }^{1}$ Dirk Van de Walle, ${ }^{1,2}$ Philippe Kiss, ${ }^{1,2}$ Marc De Meester. 'Securex Health and Safety, Drongen, Belgium; ${ }^{2}$ Department of Public Health, Ghent University, Ghent, Belgium

\subsection{6/oemed-2018-ICOHabstracts.74}

Introduction Occupational Health and Safety has known several waves to prevent injuries and worker's drop out. First, mainly technical measures were implemented. In the 1990's management systems introduced organisational measures. More recently, one became aware of the vital role of the individual (who uses the techniques according to the management system). The worker's behaviour (safety awareness) is the missing link between technical and organisational measures. The aim was to explore the relation between organisational culture and safety awareness.

Methods 17400 employees, working in 128 (private and public) organisations $(79.0 \%$ participation), filled out a self-completed questionnaire. Group level analyses on company level were performed to explore the relationship between organisational social capital (OSC) and 4 safety parameters: importance of safety in the organisation, presence of clear safety rules, recognition of working practices and knowing whom to turn to.

Organisations were divided according to size $(<50,50-99$, 100-199, $\geq 200$ employees). 113 organisations were grouped into 10 similar activity groups.

Prevalence rates of the considered safety parameters were calculated by organisation size and activity group.

Relationships between OSC and safety parameters were explored within same activity groups by correlation coefficients.

Results Analyses by company size revealed similar patterns in safety parameters: companies with $<50$ employees scored best, followed by companies with 100-199 employees, companies with 50-99 employees and worst in companies with $\geq 200$ employees.

Safety parameters scored best in construction and industries, while information and communication companies scored worst.

Depending on activity group and considered safety parameter highly significant correlations were found with OSC $\left(\mathrm{R}^{2}\right.$ reaching up to 0.87 ).

Discussion The results indicated a clear link between organisational culture and safety awareness according to company size, but regardless of activity group. The strong relationship between OSC and safety parameters indicates a predominant role of OSC within a preventative approach in safety management.

\section{THE VALUE OF SAFETY AND HEALTH TO SOCIETY - NEW GLOBAL AND EUROPEAN ESTIMATES OF ECONOMIC IMPACT}

${ }^{1}$ Dietmar Elsler, ${ }^{2}$ Jukka Takala, ${ }^{3}$ Jouko Remes. 'EU-OSHA, Bilbao, Spain; ${ }^{2}$ WSH, Singapore; ${ }^{3} \mathrm{FlOH}$, Helsinki, Finland

\subsection{6/oemed-2018-ICOHabstracts.75}

Introduction Establishing a reliable and comprehensive estimate of the cost to society of all occupational accidents and work- 